\title{
Chlorogenic Acid and Maize Ear Rot Resistance: A Dynamic Study Investigating Fusarium graminearum Development, Deoxynivalenol Production, and Phenolic Acid Accumulation
}

\author{
Vessela Atanasova-Penichon, ${ }^{1}$ Sebastien Pons, ${ }^{1,2,3}$ Laetitia Pinson-Gadais, ${ }^{1}$ Adeline Picot, ${ }^{1}$ \\ Gisèle Marchegay, ${ }^{1}$ Marie-Noelle Bonnin-Verdal, ${ }^{1}$ Christine Ducos, ${ }^{1}$ Christian Barreau, ${ }^{4}$ Joel Roucolle, ${ }^{2}$ \\ Pierre Sehabiague, ${ }^{2}$ Pierre Carolo, ${ }^{3}$ and Florence Richard-Forget ${ }^{1}$ \\ ${ }^{1}$ Institut National de la Recherche Agronomique (INRA), UR1264 MycSA, 71 avenue Edouard Bourlaux, 33883 Villenave \\ d'Ornon, France; ${ }^{2}$ Monsanto SAS Peyrehorade, Croix de Pardies, 40300 Peyrehorade, France; ${ }^{3}$ Euralis Semences, \\ 41000 Blois, France; ${ }^{4}$ Centre National de la Recherche Scientifique, INRA UR1264 MycSA, France
}

Submitted 15 June 2012. Accepted 6 August 2012.

Fusarium graminearum is the causal agent of Gibberella ear rot and produces trichothecene mycotoxins. Basic questions remain unanswered regarding the kernel stages associated with trichothecene biosynthesis and the kernel metabolites potentially involved in the regulation of trichothecene production in planta. In a two-year field study, $F$. graminearum growth, trichothecene accumulation, and phenolic acid composition were monitored in developing maize kernels of a susceptible and a moderately resistant variety using quantitative polymerase chain reaction and liquid chromatography coupled with photodiode array or mass spectrometry detection. Infection started as early as the blister stage and proceeded slowly until the dough stage. Then, a peak of trichothecene accumulation occurred and infection progressed exponentially until the final harvest time. Both $F$. graminearum growth and trichothecene production were drastically reduced in the moderately resistant variety. We found that chlorogenic acid is more abundant in the moderately resistant variety, with levels spiking in the earliest kernel stages induced by Fusarium infection. This is the first report that precisely describes the kernel stage associated with the initiation of trichothecene production and provides in planta evidence that chlorogenic acid may play a role in maize resistance to Gibberella ear rot and trichothecene accumulation.

Maize red ear rot or Gibberella ear rot is one of the major fungal diseases affecting maize production worldwide. The predominant species responsible for maize red ear rot in Europe is Fusarium graminearum, which can produce mycotoxins such as type B trichothecenes (TCTB), including deoxynivalenol (DON), its acetylated derivatives 3-acetyl-deoxynivalenol and

Corresponding author: V. Atanasova-Penichon;

E-mail: vessela.atanasova-penichon@bordeaux.inra.fr

* The $\boldsymbol{e}$-Xtra logo stands for "electronic extra" and indicates that two supplementary tables are published online and that Figure 5 appears in color online.

This article is in the public domain and not copyrightable. It may be freely reprinted with customary crediting of the source. The American Phytopathological Society, 2012. 15-acetyldeoxynivalenol (15-ADON), and zearalenone. A threshold for maximal DON content of unprocessed maize destined for human consumption was fixed to $1,750 \mu \mathrm{g} / \mathrm{kg}$ by the European Union (Commission Regulation [EC] number 1126/2007).

TCTB are heat-stable molecules that are not fully eliminated during the processes currently used in cereal-based food manufacturing (Hazel and Patel 2004). Thus, the best way to prevent the contamination would be to limit trichothecene biosynthesis at the field level during crop cultivation. The three major factors influencing fungal development and mycotoxin production on kernels are the environmental conditions, the agricultural practices, and the susceptibility range of genotypes (Edwards 2004). Increasing efforts in the corn seed industry started with the identification of genetic sources for maize Gibberella ear-rot resistance. Several approaches are currently under investigation and, among them, the identification of naturally occurring mechanisms in plants that lead to reduced mycotoxin accumulation seems particularly relevant. Boutigny and associates (2008) proposed to divide these mechanisms, reported as type V resistance, into two components: $\mathrm{V}-1$, resistance to trichothecene accumulation by metabolic transformation of the toxin, and $\mathrm{V}-2$, resistance via inhibition of trichothecene biosynthesis. As an example of type $\mathrm{V}-1$ resistance, some wheat and maize lines were found to convert DON into the less toxic DON-3- $\beta$-Dglucoside (Berthiller et al. 2009). With regards to type V-2 resistance, the ability of various plant endogenous compounds, either constitutive or induced in response to pathogen infection, to inhibit TCTB biosynthesis has been largely illustrated in the literature (Boutigny et al. 2008). Recent metabolomic analysis aimed at comparing the metabolite abundance in mature kernels of resistant versus susceptible genotypes of barley and wheat (Bollina et al. 2010; Kumaraswamy et al. 2011) have led to the identification of candidate compounds belonging to four main metabolic pathways: fatty acid, phenylpropanoid, flavonoid, and terpenoid. The arguments in favor of an involvement of phenylpropanoids (mainly phenolic acids such as caffeic, ferulic, $p$-coumaric, and sinapic acids) in type $\mathrm{V}$ resistance are numerous, the most prominent of which is their in vitro ability to reduce fungal growth and TCTB accumulation (Boutigny et al. 2009). In kernels, phenolic acids are present in both soluble (free) and insoluble (bound to cell wall polysaccharides) forms. In response to pathogen infection, they are re- 
leased from the cell wall or massively synthesized by the plant to accumulate rapidly at the site of infection (Nicholson and Hammerschidt 1992). Phenolic acids operate in defense response through direct interference with the fungus, or through the reinforcement of plant structural components to act as a mechanical barrier against the pathogen (Siranidou et al. 2002). Several studies focused on the occurrence of a correlation between resistance to Fusarium spp., trichothecene accumulation, and phenolic acid content in harvested mature maize kernels (Assabgui et al. 1993; Eggert et al. 2010). Thus far, none has dynamically described the phenolic acid mixture that $F$. graminearum encounters during active toxin production on maize. In addition, the time course of $F$. graminearum development and trichothecene accumulation in developing maize kernels has yet to be precisely defined. Indeed, although a previous field study monitored $F$. graminearum growth and DON accumulation in maize kernels (Reid and Sinha 1998), the kinetics of fungal development and the accurate kernel stage at which DON production is initiated were not identified.

In the present study, $F$. graminearum growth, trichothecene accumulation, and both free and cell-wall-bound phenolic
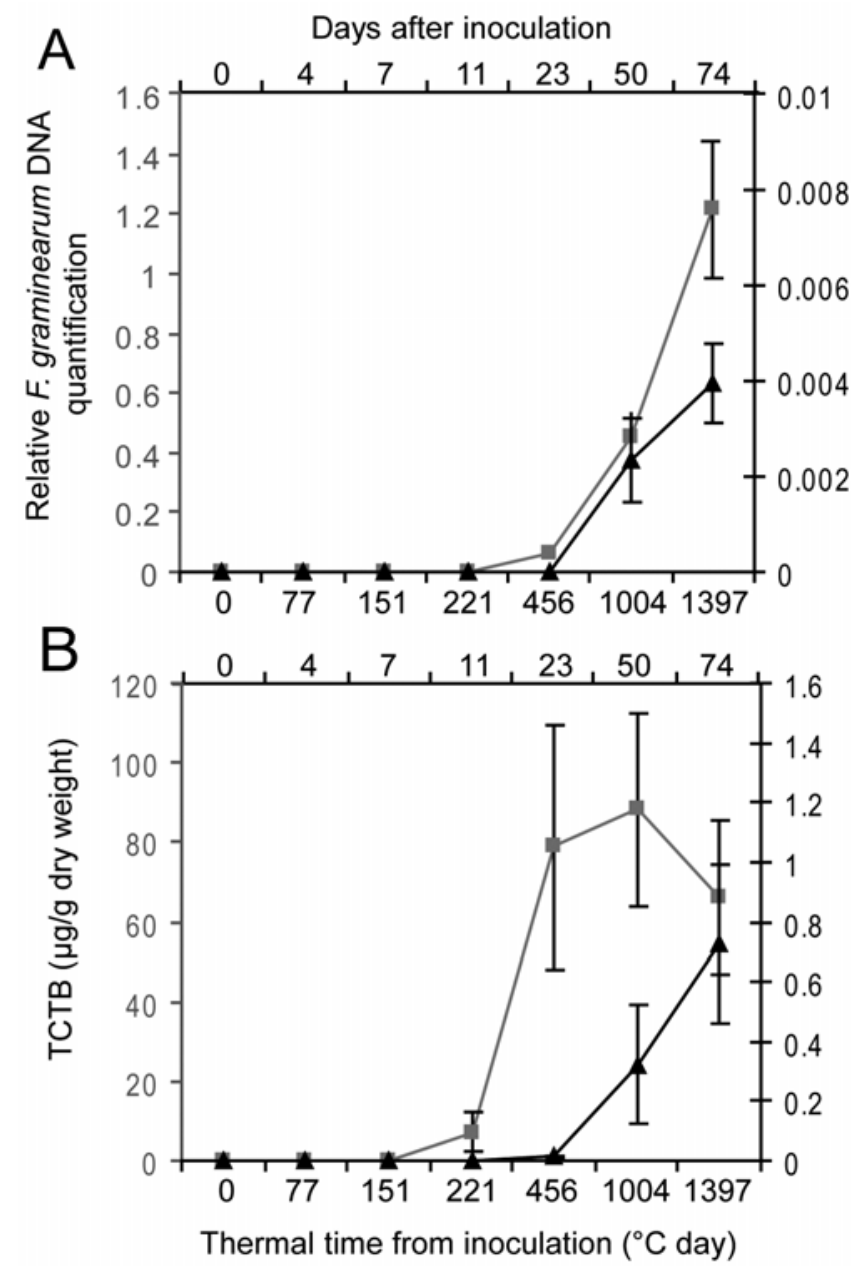

Fig. 1. A, Relative quantification of fungal DNA in maize kernels, expressed as a $\log _{10}$ (Fusarium graminearum DNA/maize DNA) ratio of V1 variety (gray squares, left $y$ axis) and V2 variety (black triangles, right $y$ axis ), and $\mathbf{B}$, level of trichothecenes accumulated in maize kernels of V1 variety (gray squares, left $y$ axis) and V2 variety (black triangles, right $y$ axis) after silk inoculation with $F$. graminearum. Vertical bars show standard error of the mean. Bottom $x$ axis: thermal time from inoculation (mean value of two years and two varieties), top $x$ axis; dai $=$ days after inoculation for each sampling (mean value of two years and two varieties). For each variety, data from the two years and two repetitions were pooled (mean values \pm standard error of the mean, $n=4$ ). composition were monitored after silk inoculation throughout the various stages of maize kernel development, up to harvest. The main objectives were to i) identify when fungal colonization and trichothecene production are initiated in maize ears, ii) investigate how they evolve up to plant maturity together with phenolic acid content, and iii) relate phenolic acid content to DON production over the course of maize kernel colonization in order to validate previous in vitro results that proposed phenylpropanoids as potential biomarkers for type $\mathrm{V}$ resistance to maize ear rot.

\section{RESULTS}

\section{Fungal development and trichothecene accumulation} in developing maize kernels.

Maize kernels were sampled at different harvest times after silk inoculation with $F$. graminearum. For each sample, fungal growth was estimated by the proportion of $F$. graminearum genomic DNA (gDNA) relative to maize gDNA that was detected by quantitative polymerase chain reaction (Q-PCR). In addition, trichothecene accumulation was quantified by highperformance liquid chromatography (HPLC) tandem mass spectrometry (MS/MS).

The onset of fungal infection in the susceptible V1 variety was detected early, at blister stage ( 7 days after inoculation [dai]), and became measurable at dough stage (23 dai) (Fig. 1A). With regards to the moderately resistant V2 variety, the onset of fungal infection occurred later, between 23 and 50 dai (early dent stage) (Fig. 1A). In both varieties, fungal growth following onset seemed to be exponential. At maturity, the level of $F$. graminearum gDNA was 300 times lower in the moderately resistant V2 variety than in the V1 variety. It is worth noting that $F$. graminearum is able to massively colonize the maize kernels up to the final harvest, at physiological stages characterized by kernel moisture content inferior to $40 \%$.

TCTB content was measured in the same samples. DON always represented 95 to $98 \%$ of the total toxins in each sample. We first quantified TCTB levels in V1 susceptible kernels at 11 dai (milk stage) with an amount of $7 \mu \mathrm{g} / \mathrm{g}$ (Fig. 1B). Then, toxin levels reach a maximum level close to $80 \mu \mathrm{g} / \mathrm{g}$ at 23 dai (dough stage) that remained stable until final harvest time. In the moderately resistant V2 variety, TCTB were first detected at 23 dai, with levels continuously increasing until a maximum was reached after 50 dai $(0.7 \mu \mathrm{g} / \mathrm{g})$ (Fig. 1B). TCTB levels in the moderately resistant $\mathrm{V} 2$ variety were approximately 200 times lower than those in susceptible V1 kernels. Regardless of the scale of TCTB and $F$. graminearum gDNA levels, exponential growth of $F$. graminearum starts when TCTB have already attained their maximum amount (Fig. 1). In other words, TCTB synthesis precedes exponential growth. On control plants, only trace amounts of $F$. graminearum gDNA and TCTB were detected, below the quantification limit of LCMS/MS (data not shown).

\section{Free phenolic acids in developing kernels.}

Phenolic acid content in maize kernels of both varieties was monitored from silking through harvest maturity by LC/photodiode array detector (DAD) and LC/electrospray ionization (ESI)-MS. No qualitative differences were observed between the two varieties whatever the considered developing stage, and typical chromatograms of the free phenolic acids extracted from infected silking and mature maize samples (V2 variety) are reported on Figure 2. For both varieties, strong qualitative variations were observed between the developing stages analyzed. Six main phenolic acids were detected in immature kernels: chlorogenic $[\mathrm{M}-\mathrm{H}]^{-} m / z, 353$, caffeic $[\mathrm{M}-\mathrm{H}]^{-} \mathrm{m} / z$, 179, vanillic $[\mathrm{M}-\mathrm{H}]^{-} \mathrm{m} / \mathrm{z} 167, p$-coumaric $[\mathrm{M}-\mathrm{H}]^{-} \mathrm{m} / \mathrm{z}$ 163, trans- 
ferulic $[\mathrm{M}-\mathrm{H}]^{-} \mathrm{m} / \mathrm{z}, 193$, and sinapic $[\mathrm{M}-\mathrm{H}]^{-} \mathrm{m} / \mathrm{z} 223$ acids. With regards to mature kernels, two hydrophobic compounds with UV-VIS spectra typical of cinnamic acid derivatives eluted at 42.8 and 43.4 min. Mass spectrometry data obtained by LC/ESI-MS in the negative ion mode showed signals at $\mathrm{m} / \mathrm{z}$ 409 and $m / z$ 439, respectively. On the basis of the UV-VIS spectra and MS/MS fragmentation patterns, these compounds were identified as the hydroxycinnamic polyamines $p$-coumaroyl-feruloylputrescine (CFP) and diferuoylputrescine (DFP) (Moreau et al. 2001). CFP and DFP represented the main peaks in chromatograms of mature kernels of both varieties. We followed and compared the variations of chlorogenic, caffeic, ferulic, $p$-coumaric, sinapic, and vanillic acids contents as well as CFP and DFP contents in developing kernels of the V1 and V2 maize varieties, both infected and noninfected (Fig. 3; Supplementary Table S2).

Accumulation of free phenolic acids throughout the development of noninoculated maize kernels. Whatever the variety considered and with the exception of $p$-coumaric acid (Fig. $3 \mathrm{~F}$ ), changes in free phenolic acids followed a similar pattern. A gradual decrease in chlorogenic, ferulic, vanillic, caffeic, and sinapic acids occurred from the silking stage through maturity (Fig. 3A, B, C, E, and G). Decrease in sinapic acid started later, between 11 and 23 dai. From 23 dai to maturity, only trace amounts of free hydroxycinnamic acids were detected whereas CFP and DFP accumulated to finally represent the major soluble compounds in mature kernels (Fig. 3H). In agreement with a previous report (Choi et al. 2007), the ratio of CFP to DFP was close to 1:3. At maturity, the sum of CFP+DFP concentrations reached $170 \mu \mathrm{g} / \mathrm{g}$ for the V1 variety and $330 \mu \mathrm{g} / \mathrm{g}$ for the V2 variety. Analysis of variance (ANOVA) exhibited significant differences among the sampling dates for all compounds $(P<0.0001)$, with the exception of $p$-coumaric acid in the V1 variety, whose level remained stable close to $5 \mu \mathrm{g} / \mathrm{g}$.

During the first stages of kernel development (from silking to milk stages), chlorogenic acid clearly appeared as the predominant free phenolic acid regardless the variety. In the V2 variety, levels of chlorogenic acid reached $1,100 \mu \mathrm{g} / \mathrm{g}$ at 4 dai, representing $85 \%$ of the total soluble phenolic acids, whereas only $110 \mu \mathrm{g} / \mathrm{g}$ (or $56 \%$ of the total soluble phenolic acids) were detected in the V1 variety. Immature kernels were also characterized by high levels of ferulic and caffeic acids, the sum of which equaled 36 and $12 \%$ of total free phenolic acids at 4 dai for the V1 and V2 varieties, respectively. In contrast, regardless of the development stage and the variety considered, the combined levels of vanillic, $p$-coumaric, and sinapic acids never represented more than $10 \%$ of the total content in free phenolic acids.

Significant differences in the level of free phenolic acids between varieties were mainly observed for the first stages of kernel development ( 0 to 23 dai). Free phenolic acid content in V2 kernels was 3- to 10-fold higher than in V1 $(P<0.05)$. This difference was mainly ascribed to chlorogenic and ferulic acid content (Fig. 3A and B). Chlorogenic acid concentration in V2 varied from $1,100 \mu \mathrm{g} / \mathrm{g}$ at silking stage to $250 \mu \mathrm{g} / \mathrm{g}$ at milk stage whereas it never exceeded $160 \mu \mathrm{g} / \mathrm{g}$ in the susceptible V1 variety. A similar trend was observed for ferulic acid, whose content was two to four times higher in immature kernels of the moderately resistant V2 variety. From dough stage to the last sampling, differences in chlorogenic and ferulic acid contents between V1 and V2 were not significant anymore. Regarding vanillic and $p$-coumaric acids, differences between the two varieties were less obvious, even though levels remained higher in V2 compared with V1 during the first stages of kernel development (Fig. 3C and F). The only exception to this trend was caffeic acid content at silking stage, which was detected in greater concentrations in the susceptible V1 variety (83 compared with $32 \mu \mathrm{g} / \mathrm{g}$ in V2). There was no significant difference afterward from blister stage through maturity (Fig. $3 \mathrm{E})$. Sinapic acid contents were dispersed in both varieties, probably due to low levels, close to the limit of quantification of our LC analysis (Fig. 3G). Finally, CFP and DFP were present in equivalent amounts for both varieties.

Changes in free phenolic acid content following inoculation. Phenolic acid content in the V1 variety was not significantly affected by Fusarium inoculation, with the exception of chlorogenic acid at the blister and milk stages (Fig. 3A). Fusarium infection led to an increase in chlorogenic acid concentration of between 30 and $50 \mu \mathrm{g} / \mathrm{g}$. A similar trend was observed for

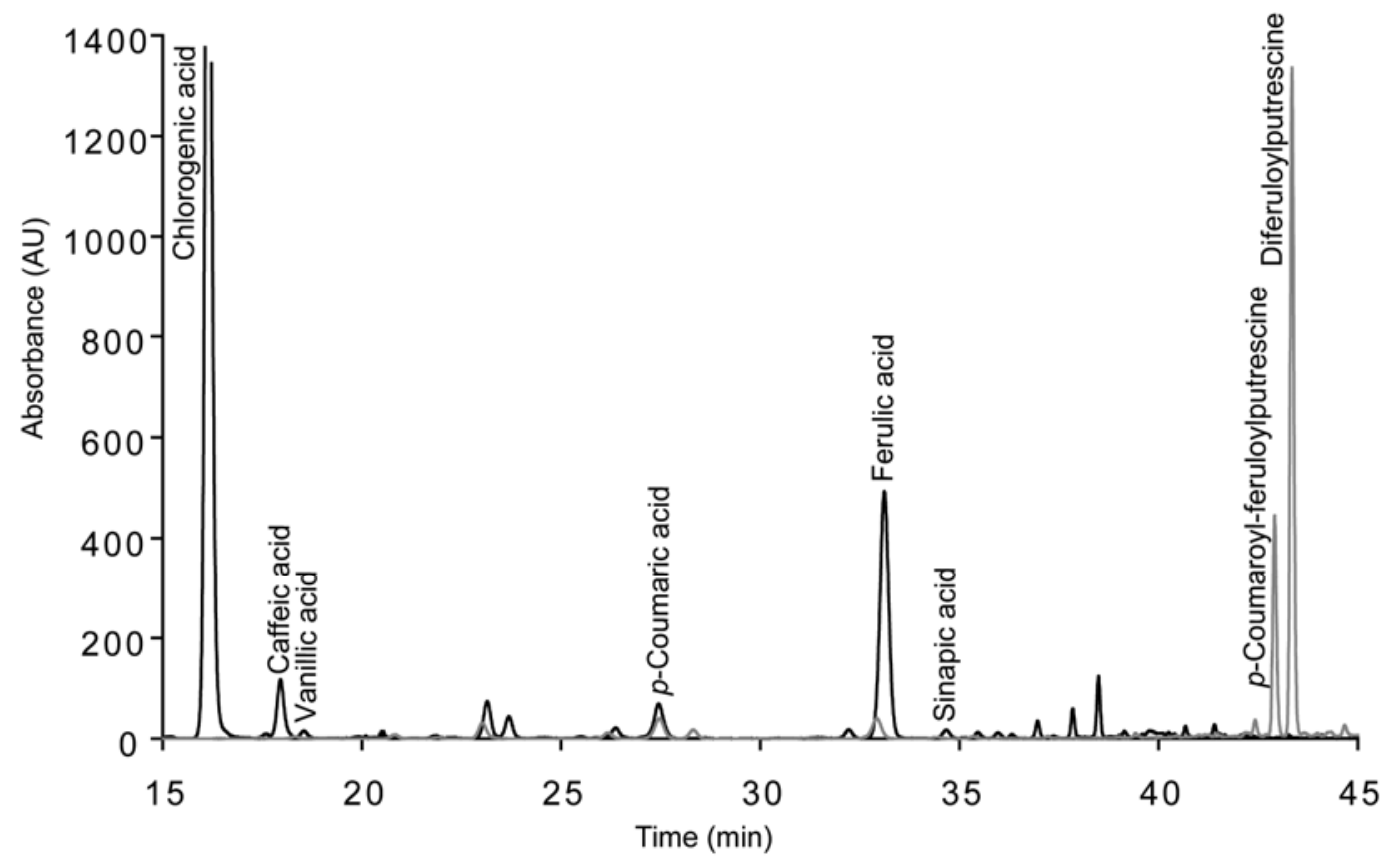

Fig. 2. High-performance liquid chromatography chromatograms at $320 \mathrm{~nm}$ of free phenolic fraction of inoculated moderately resistant V2 sample at 4 days after inoculation (black) and at maturity (gray). 
the V2 variety, with an increased concentration of chlorogenic acid after inoculation that reached a value close to $2,200 \mu \mathrm{g} / \mathrm{g}$ at the silking stage (4 dai). For this last variety, at the blister stage ( 7 dai), the difference between treatments for chlorogenic acid level (close to $300 \mu \mathrm{g} / \mathrm{g})$ was only tendentious $(P<$ $0.10)$. F graminearum inoculation also induced a significant increase in ferulic ( 7 dai) and caffeic acid contents (4 dai) in kernels of the V2 variety (Fig. 3B and E). In addition, a twofold increase at 4 dai in vanillic and $p$-coumaric acids contents was observed but the differences were not significant (Fig. 3C and F). In contrast, sinapic acid exhibited nonsignificant differences between treatments (Fig. 3G). With regard to hy-
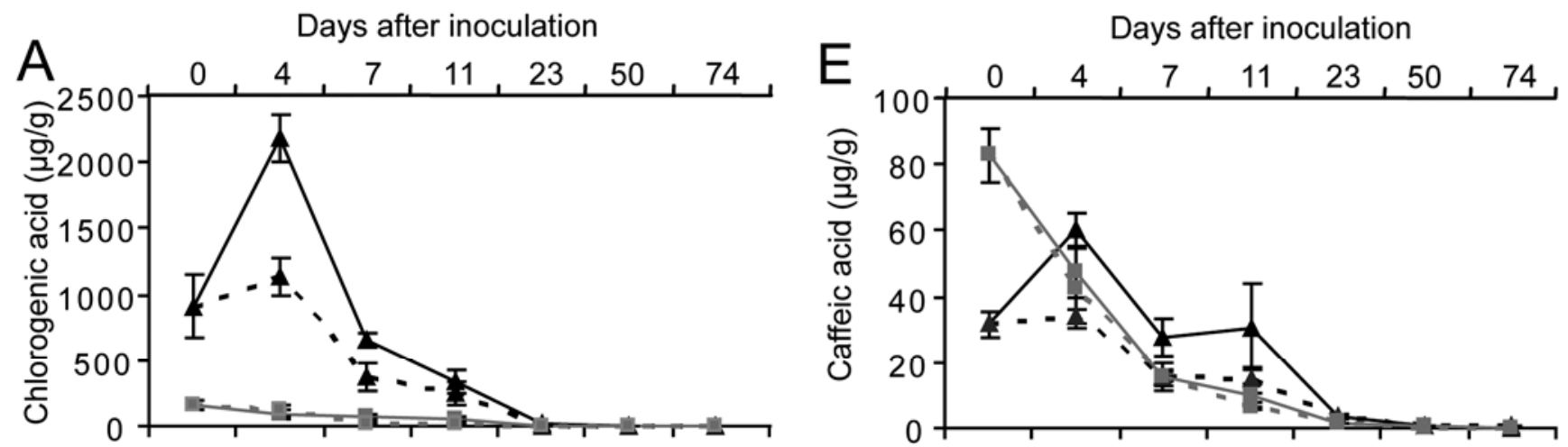

B
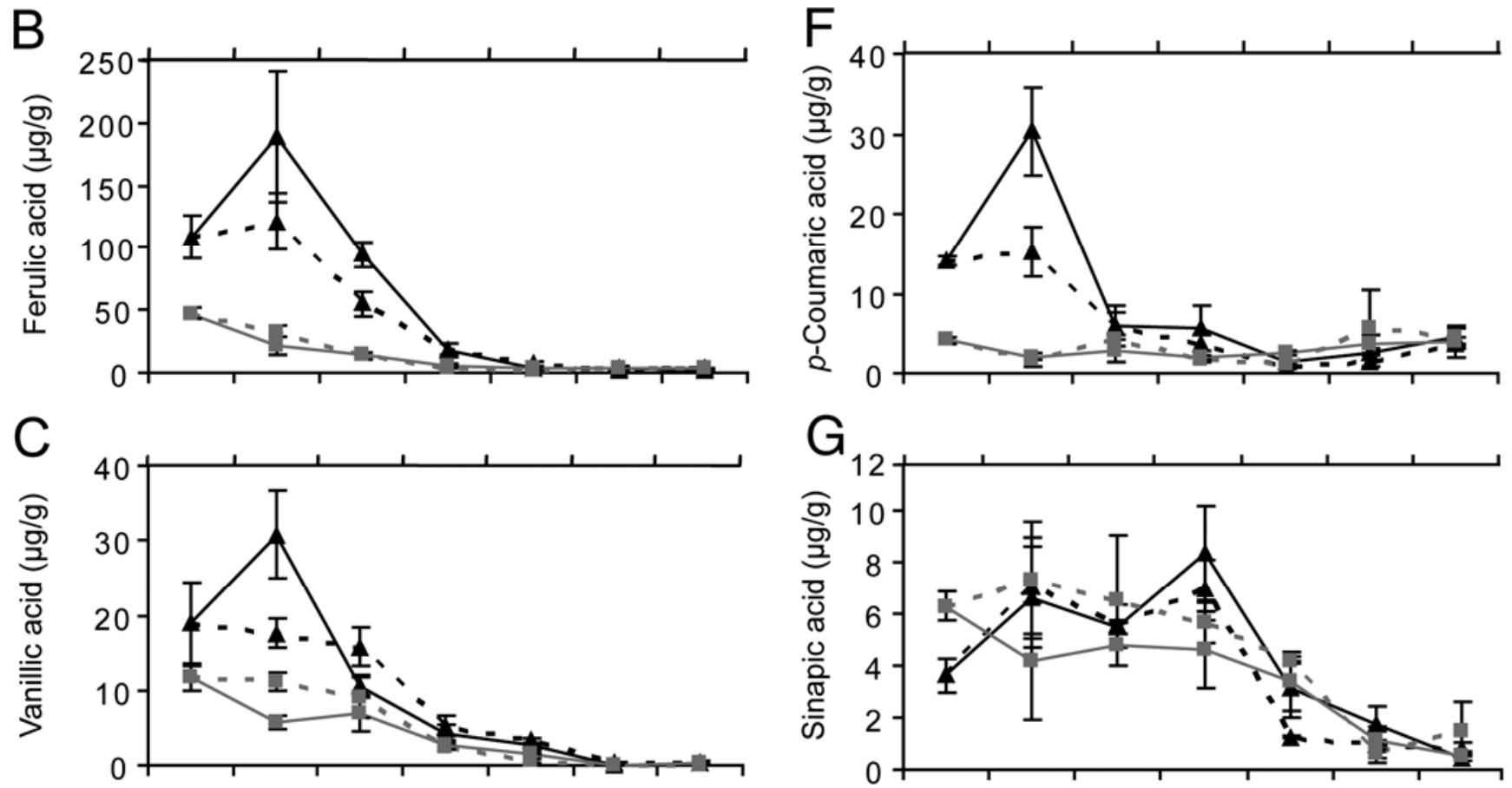

D

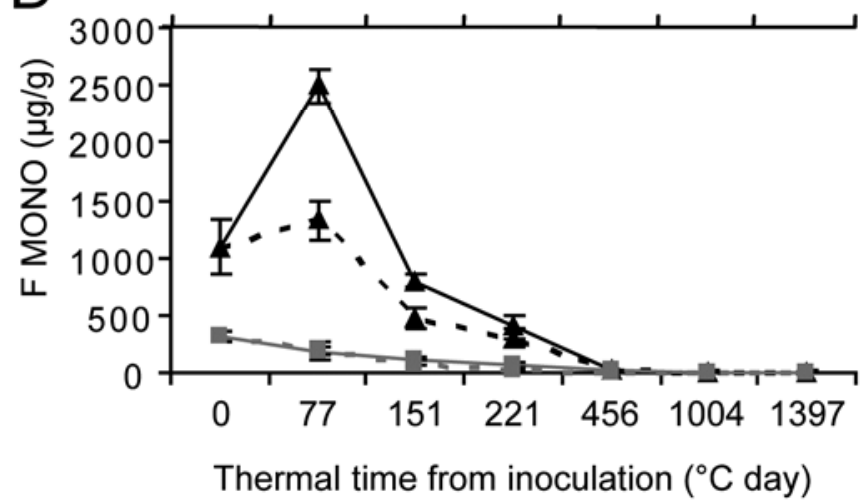

$\mathrm{H}$

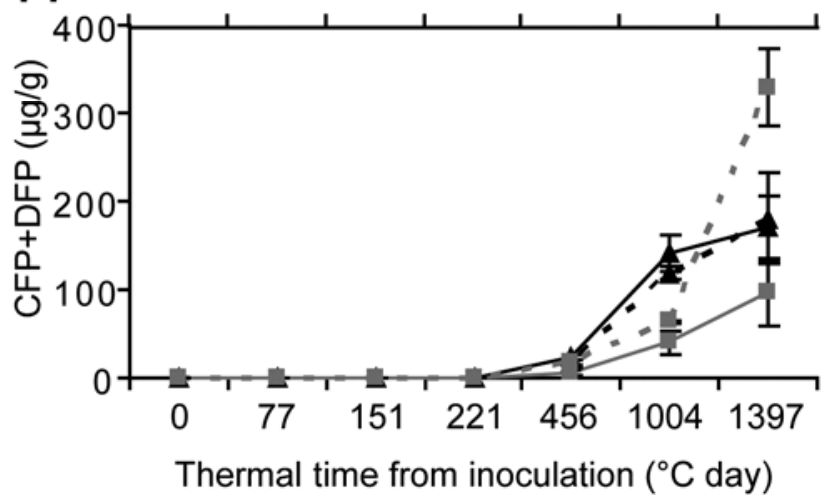

Fig. 3. Kinetics of A, chlorogenic acid; B, ferulic acid; $\mathbf{C}$, vanillic acid; $\mathbf{D}$, sum of all free phenolic acid monomers (F MONO); E, caffeic acid; $\mathbf{F}$, -coumaric acid; G, sinapic acid; and $\mathbf{H}$, sum of p-coumaroyl-feruloylputrescine (CFP) and diferuoylputrescine (DFP) detected in maize kernels after silk inoculation with Fusarium graminearum (solid line) and control (dotted line) of V1 (gray squares) and V2 (black triangles) varieties. Vertical bars show standard error of the mean. Bottom $x$ axis: thermal time from inoculation (mean value of two years and two varieties) and top $x$ axis: days after inoculation for each sampling (mean value of two years and two varieties). For each variety, data from the two years and two repetitions were pooled (mean values \pm standard error of the mean, $n=4)$. 
droxycinnamic polyamines (CFP + DFP), their concentration was similar or higher in kernels of the V2 variety whereas inoculation seemed to induce a decrease in their accumulation for the V1 variety (Fig. 3H).

According to the former observations, the differences in phenolic compound concentrations between the two studied varieties were largely higher when infected kernels were compared instead of noninfected samples. Four days after F. graminearum inoculation, the sum of phenolic acid monomers was 15-fold higher in kernels of the V2 variety than in kernels of the V1 one (Fig. 3D).

\section{Cell-wall-bound phenolic acids in developing kernels.}

A typical chromatogram of esterified phenolic acids from maize kernels is shown in Figure 4. Three major hydroxycinnamic acid-derived monomers are present: ferulic, $p$-coumaric, and sinapic acids. In addition to these monomeric forms, several peaks eluted at the end of the chromatogram with a [M$\mathrm{H}]^{-} \mathrm{m} / z$, signal equal to 385 . Based on the UV-VIS and mass spectra, these compounds were assigned to ferulic acid dehydrodimers (DiFA) and were identified as 8-5' DiFA (open form) and 5-5' DiFA, 8-O-4' DiFA, and 8-5' benDiFA (benzofuran form) (Bunzel 2010; Bunzel et al. 2006).

We measured the levels of esterified phenolic acids in developing kernels, from silking to maturity, from the V1 and V2 varieties. Concentrations in ferulic, $p$-coumaric, and sinapic acids, the sum of DiFA, and the sum of phenolic acid monomers (MONO) are summarized in Table 1. Because no significant differences were observed between infected samples and their respective control ones, data reported in Table 1 only concern the inoculation treatment. The sum of hydroxycinnamic acid monomers released by alkaline treatment of the cellwall-esterified phenolic fractions (MONO) ranged between 1,500 and $11,000 \mu \mathrm{g} / \mathrm{g}$, depending on the considered variety and kernel stage. These concentrations were significantly higher than the free phenolic acid amounts previously determined in developing kernels. Ferulic and $p$-coumaric acids were the most abundant. Ferulic acid was the major cell-wallbound phenolic acid in kernels at all stages of development, representing between 75 and $95 \%$ of the total cell-wall-bound monomeric phenolic contents. Percentages of $p$-coumaric acid ranged between 5 and $25 \%$ while sinapic acid concentrations did not exceed $3 \%$ of the total. Regarding the DiFA, the predominant ones were 8-O-4' DiFA and 8-5' benDiFA, followed by $5-5^{\prime}$ DiFA and $8-5^{\prime}$ DiFA $(33,32,25$, and $10 \%$ of the total DiFA, respectively, in all the developing stages of both V1 and V2 varieties) (data not shown).

Accumulation of ferulic and $p$-coumaric acids from silking to maturity followed a similar kinetic in both V1 and V2 varieties. Significant differences among harvest times were observed. From silking, ferulic and $p$-coumaric acid levels increased to reach a maximum at 7 to 11 dai (blister to milk stage). Ferulic acid concentrations reached $6,100 \mu \mathrm{g} / \mathrm{g}$ in V1 kernels and $8,500 \mu \mathrm{g} / \mathrm{g}$ in $\mathrm{V} 2$ kernels; $p$-coumaric acid maximum levels reached $1,500 \mu \mathrm{g} / \mathrm{g}$ in $\mathrm{V} 1$ kernels and $2,745 \mu \mathrm{g} / \mathrm{g}$ in V2 kernels. From milk stage, a drastic decrease in ferulic and $p$-coumaric acid levels was observed. In contrast, in the case of sinapic acid, concentrations from silking through maturity slowly increased from 5 to $50 \mu \mathrm{g} / \mathrm{g}$ for the last sampling. With regards to DiFA, levels increased up to $1,200 \mu \mathrm{g} / \mathrm{g}$ from silking through the milk stage (11 dai) for both varieties. After milk stage and until maturity, levels in DiFA remained stable in V1 kernels but decreased in V2 kernels.

All results considered together, significant differences between varieties were mainly observed during the first stages of kernel development, from 0 to 7 dai. The moderately resistant V2 variety has nearly twice the ferulic acid, $p$-coumaric acid, and DiFA from inoculation time through the blister stage ( 7 dai) than the susceptible V1 variety. This difference was significant for $p$-coumaric acid at 0 and 7 dai, for ferulic acid at 0 dai, and for DiFA at 0,4 , and 7 dai. At maturity, kernels of the V2 variety contained the lowest amounts of DiFA, with a difference of $350 \mu \mathrm{g} / \mathrm{g}$ between both varieties.

\section{DISCUSSION}

The present work is the first report that accurately describes kinetics of $F$. graminearum development and TCTB accumulation in maize kernels in field experiments. Environmental conditions during the 2007 and 2008 growing seasons in the south-

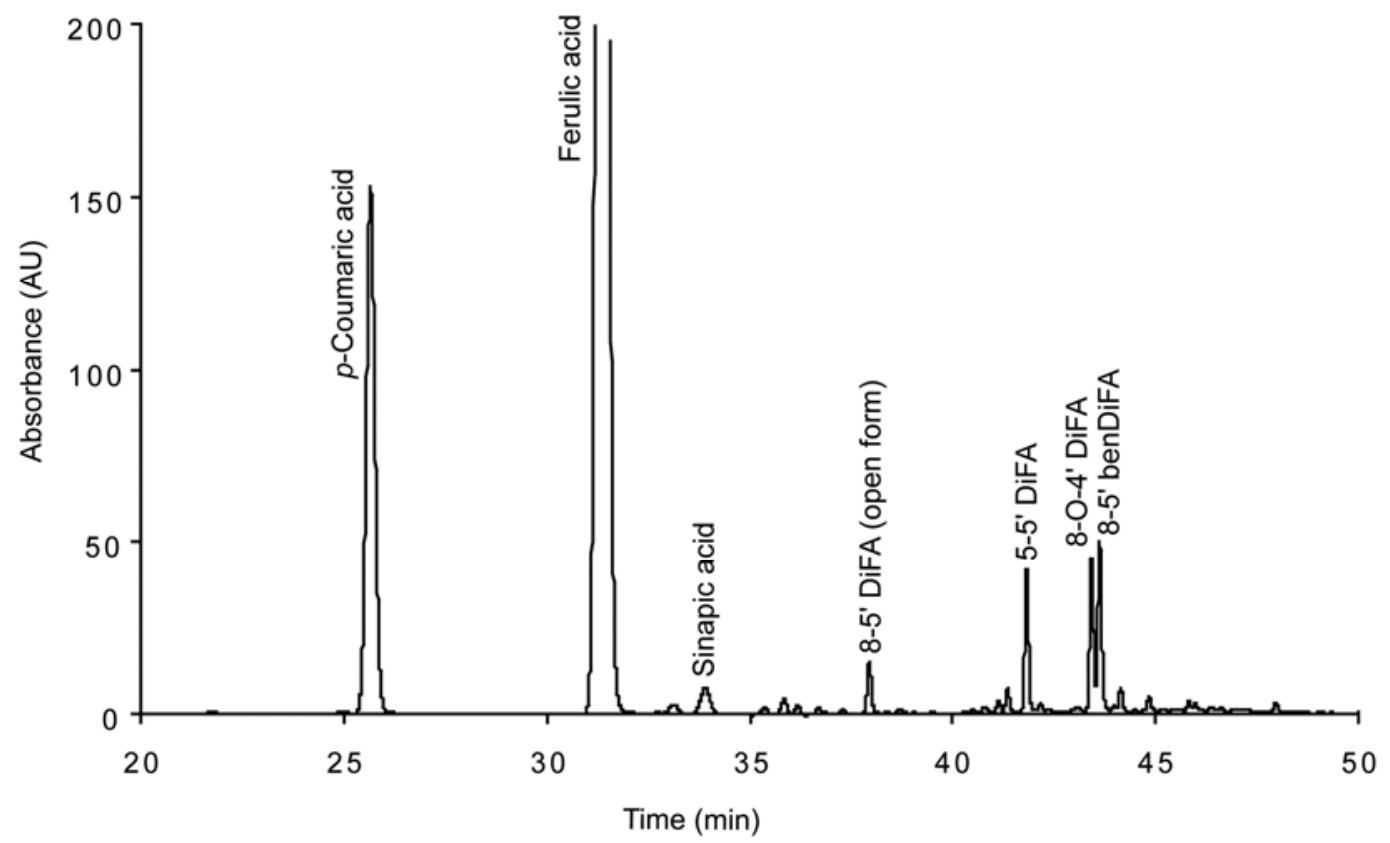

Fig. 4. High-performance liquid chromatography chromatogram at $320 \mathrm{~nm}$ of cell-wall-bound phenolic fraction of inoculated V1 sample at 7 days after inoculation. 
west of France, together with the $F$. graminearum strain and the toothpick inoculation procedures we used, led to severe ear-rot symptoms, substantial fungal infection, and high DON concentrations in the susceptible variety while allowing the expression of resistance with the second variety. Combining all of our in planta results, we schematized the chronology of fungal infection and TCTB accumulation (Fig. 5).

\section{Initiation of in planta DON accumulation.}

In our experiments, fungal gDNA was first detected between the blister stage ( 7 dai) and the dough-dent stage (23 to 50 dai), depending on the considered variety. These data are in accordance with the previous report of Reid and Sinha (1998), who observed the first Gibberella ear-rot disease symptoms three weeks after silking. Similar results were also described for $F$. verticillioides infection (Picot et al. 2011). Regardless the variety, we observed that $F$. graminearum infection initiated rather slowly, followed by an exponential phase of infection until final harvest time (Fig. 5A). Initial contamination of DON occurred between 7 and 11 dai for the susceptible variety and 11 and 23 dai for the moderately resistant one. In other words, DON was first detected at the same stage as the fungal
gDNA was first reliably detected, or even earlier for the lesssensitive variety. In the study performed by Reid and Sinha (1998), DON quantification was performed by an enzymelinked immunosorbent assay method, that was certainly not sensitive enough to allow DON measurement before milk stage. Our results greatly refine this measure. The accurate and sensitive quantification method we used shows that the initiation of DON production can occur before 11 dai. Following initial detection, DON accumulation drastically increased to reach a plateau after 23 dai for the susceptible V1 variety; meanwhile, it gradually increased until the last sampling date for the moderately resistant V2 one. Comparing fungal growth and DON production, it clearly appears that DON accumulation preceded the exponential phase of growth (Fig. 5A). This observation is particularly obvious for the susceptible variety and remains true for the moderately resistant one, where DON was detected before fungal gDNA. This observation could suggest that DON facilitates $F$. graminearum colonization of maize tissues. Nonetheless, whereas field and growth-chamber trials performed by Harris and associates (1999) and Asran and Buchenauer (2003) have led to a similar hypothesis, other publications propose that DON production has no influence on

Table 1. Mean concentrations at seven harvest times of the major cell-wall-bound phenolic compounds in the inoculate maize of V1 and V2 varieties

\begin{tabular}{|c|c|c|c|}
\hline \multirow[b]{2}{*}{ Compound, harvest time $(\text { dai })^{y}$} & \multicolumn{2}{|c|}{ Concentrations $\left(\mu \mathrm{g} / \mathrm{g}\right.$ dry weight) per variety ${ }^{\mathrm{x}}$} & \multirow[b]{2}{*}{$P$ value $^{\mathrm{z}}$} \\
\hline & V1 inoculated & V2 inoculated & \\
\hline \multicolumn{4}{|l|}{ Ferulic acid } \\
\hline 0 & $1,448.6 \pm 93.2 \mathrm{bc}$ & $2,893.7 \pm 403.6 \mathrm{c}$ & 0.0086 \\
\hline 4 & $2,503.2 \pm 667.9 \mathrm{~b}$ & $5,259.1 \pm 1183.9 b$ & 0.0800 \\
\hline 7 & $5,975.8 \pm 1214.8 \mathrm{a}$ & $8,117.9 \pm 916.1 \mathrm{a}$ & 0.1889 \\
\hline 11 & $6,143.3 \pm 1246.3 \mathrm{a}$ & $8,455.3 \pm 500.1 \mathrm{a}$ & 0.1353 \\
\hline 23 & $2,033.5 \pm 122.5 \mathrm{bc}$ & $3,486.8 \pm 449.9 \mathrm{bc}$ & 0.0119 \\
\hline 50 & $1,303.9 \pm 129.2 \mathrm{c}$ & $1,822.2 \pm 434.4 \mathrm{~d}$ & 0.3938 \\
\hline 74 & $1,345.4 \pm 127.2 \mathrm{c}$ & $1,419.3 \pm 79.5 \mathrm{~d}$ & 0.6051 \\
\hline \multicolumn{4}{|l|}{$p$-Coumaric acid } \\
\hline 0 & $332.9 \pm 26.1 \mathrm{c}$ & $545.2 \pm 22.7 \mathrm{~b}$ & 0.0013 \\
\hline 4 & $456.1 \pm 49 \mathrm{c}$ & $748.3 \pm 119.8 \mathrm{~b}$ & 0.0504 \\
\hline 7 & $965.5 \pm 140.2 \mathrm{~b}$ & $2,745.4 \pm 254.3 \mathrm{a}$ & 0.0007 \\
\hline 11 & $1,537.3 \pm 313.4 \mathrm{a}$ & $2,596.4 \pm 574.4 \mathrm{a}$ & 0.0178 \\
\hline 23 & $209.1 \pm 33.9 \mathrm{~d}$ & $170.1 \pm 13.3 \mathrm{c}$ & 0.3538 \\
\hline 50 & $177.4 \pm 40.1 \mathrm{~d}$ & $143.9 \pm 32.8 \mathrm{c}$ & 0.5099 \\
\hline 74 & $209.1 \pm 10.7 \mathrm{~d}$ & $157.1 \pm 18.6 \mathrm{c}$ & 0.0704 \\
\hline \multicolumn{4}{|l|}{ Sinapic acid } \\
\hline 0 & $4.2 \pm 2.5 \mathrm{bc}$ & $4.7 \pm 1.8 \mathrm{~b}$ & 0.6074 \\
\hline 4 & $5.4 \pm 3.0 \mathrm{~b}$ & $10.9 \pm 6.3 b$ & 0.8472 \\
\hline 7 & $4.4 \pm 1.4 \mathrm{a}$ & $10.7 \pm 6.2 \mathrm{~b}$ & 0.3285 \\
\hline 11 & $5.3 \pm 3.0 \mathrm{a}$ & $12.0 \pm 7.8 \mathrm{~b}$ & 0.8919 \\
\hline 23 & $23.6 \pm 6.5 \mathrm{bc}$ & $24.2 \pm 4.6 \mathrm{ab}$ & 0.8188 \\
\hline 50 & $49.0 \pm 2.0 \mathrm{c}$ & $37.5 \pm 12.3 \mathrm{ab}$ & 0.3188 \\
\hline 74 & $51.6 \pm 6.5 \mathrm{c}$ & $43.5 \pm 7.2 \mathrm{a}$ & 0.4073 \\
\hline \multicolumn{4}{|l|}{ MONO } \\
\hline 0 & $1,785.7 \pm 114.3 \mathrm{bc}$ & $3,443.7 \pm 413.3 \mathrm{c}$ & 0.0049 \\
\hline 4 & $2,964.6 \pm 714.5 \mathrm{~b}$ & $6,018.3 \pm 1309.2 \mathrm{~b}$ & 0.0769 \\
\hline 7 & $6,942.7 \pm 1353.5 \mathrm{a}$ & $10,874.2 \pm 1087.6 \mathrm{a}$ & 0.0676 \\
\hline 11 & $7,685.9 \pm 1489.3 \mathrm{a}$ & $11,063.7 \pm 1015.8 \mathrm{a}$ & 0.1130 \\
\hline 23 & $2,266.2 \pm 106.1 \mathrm{bc}$ & $3,681.0 \pm 459.7 b c$ & 0.0147 \\
\hline 50 & $1,530.2 \pm 160.4 \mathrm{c}$ & $2,003.5 \pm 479.5 \mathrm{~d}$ & 0.5235 \\
\hline 74 & $1,606.1 \pm 140.1 \mathrm{c}$ & $1,619.8 \pm 98.8 \mathrm{~d}$ & 0.8986 \\
\hline \multicolumn{4}{|l|}{ DiFA } \\
\hline 0 & $368.0 \pm 28.7 \mathrm{c}$ & $692.2 \pm 67.2 \mathrm{bc}$ & 0.0020 \\
\hline 4 & $536.2 \pm 63.8 \mathrm{bc}$ & $927.0 \pm 98.1 \mathrm{ab}$ & 0.0188 \\
\hline 7 & $897.1 \pm 68.2 \mathrm{a}$ & $1,281.6 \pm 57.8 \mathrm{a}$ & 0.0058 \\
\hline 11 & $900.6 \pm 166.6 \mathrm{a}$ & $1,202.6 \pm 183.8 \mathrm{a}$ & 0.2862 \\
\hline 23 & $718.7 \pm 74.0 \mathrm{ab}$ & $554.8 \pm 92.5 \mathrm{c}$ & 0.2132 \\
\hline 50 & $905.8 \pm 255.6 \mathrm{a}$ & $706.7 \pm 138.1 \mathrm{bc}$ & 0.5222 \\
\hline 74 & $979.2 \pm 39.6 \mathrm{a}$ & $627.9 \pm 36.5 \mathrm{bc}$ & 0.0009 \\
\hline
\end{tabular}

${ }^{\mathrm{x}}$ Mean values \pm standard error of the mean, $n=4$. DUNCAN for comparisons between harvest times. Means in the same column followed by different letters are significantly different $(P<0.05)$.

${ }^{\mathrm{y}}$ Harvest time $=$ days after inoculation (dai), $\mathrm{MONO}=$ sum of phenolic acid monomers (ferulic, $p$-coumaric, and sinapic acids), and DiFA $=$ sum of ferulic acid dimers (8-5'DiFA, 5-5'DiFA, 8-O-4'DiFA, and 8-5'benDiFA).

${ }^{\mathrm{z}} P$ (Student's test) for comparisons between V1 and V2 varieties of inoculated samples. Significant differences are indicated in bold $(P<0.05)$. 
maize infection (Carter et al. 2002; Maier et al. 2006). According to the latter authors, virulence of $F$. graminearum strains in maize is controlled by several factors, including a secreted lipase and the toxin nivalenol but not DON. Therefore, the role of DON as virulence factor on maize remains under debate, although its ability to facilitate colonization of wheat heads during Fusarium head blight was clearly demonstrated (Bai et al. 2001).

Chlorogenic and ferulic acids are the predominant phenolic compounds that $F$. graminearum is likely to encounter when DON production is initiated.

In the present study, both $F$. graminearum gDNA and TCTB levels are 300 and 200 times higher in the susceptible variety than in the more resistant one, respectively, supporting the initial resistance evaluation performed by Arvalis-Institut du Végétal under natural contamination. In a search for possible causes for these differences, we investigated the occurrence of endogenous maize components able to modulate fungal development or DON accumulation. We focused on phenolic acids because of their frequently reported involvement in resistance to pests and diseases (Bily et al. 2003; Santiago and Malvar
2010) and their in vitro ability to inhibit the biosynthesis of various mycotoxins, including TCTB (Boutigny et al. 2009), fumonisins (Beekrum et al. 2003) aflatoxin (Nesci et al. 2007), and ochratoxin (Palumbo et al. 2007). Efficiency of phenolic acids to interact with mycotoxin biosynthesis was shown to be linked to their antioxidant properties (Ponts et al. 2011) and compared with that of phenolic-synthetic food-grade antioxidants such as butyl hydroxytoluene and butylhydroxyanisol (Chulze 2010; Ponts et al. 2011)

Kernel composition in cell-wall-bound phenolic compounds has been intensively investigated (Bily et al. 2003; McKeehen et al. 1999; Siranidou et al. 2002). However, little information is available concerning free phenolic acids, although this fraction is more likely to interfere with Fusarium spp. Up to now, no accurate data were published concerning the composition in phenolic acids of maize kernels during their first developmental stages. Our results show that composition in free phenolic acid evolves qualitatively over time whereas the composition in cell-wall-bound phenolic acids remains unchanged and only shows quantitative variation at the different kernel stages. Chlorogenic, ferulic, and caffeic acids were the main free compounds at the first stages, with chlorogenic acid representing

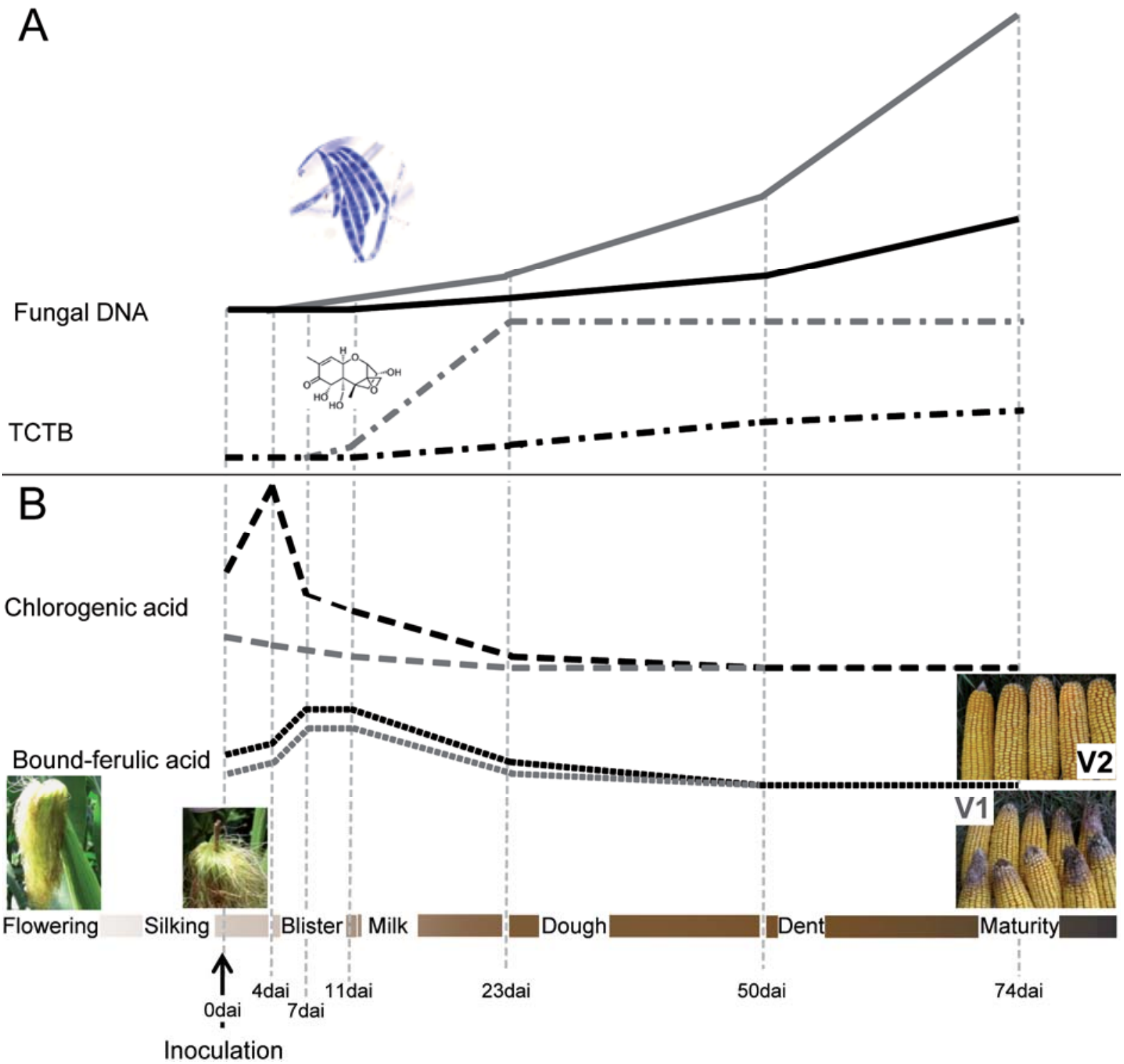

Fig. 5. Kinetics of A, Fusarium graminearum fungal growth and type B trichothecene (TCTB) accumulation and B, free chlorogenic acid and cell wall-bound ferulic acid in maize kernels of V1 (in gray) and V2 (in black) varieties; dai = days after inoculation. 
between 55 and $85 \%$ of the total depending on the stage and variety. Hydroxycinnamic polyamines, CFP and DFP, were the major free compounds from dough to harvest maturity stage. Despite their relative abundance in mature maize kernels, the physiological role of CFP and DFP has not yet been elucidated. Free phenolic acid content reached an absolute maximum at 4 dai and then progressively decreased until the last harvest time in both noninoculated and inoculated samples. Ferulic and $p$-coumaric acids were the predominant cell-wallbound phenolic acids; their abundance was maximal shortly after free phenolic acids accumulated. Ferulic acid represents more than $80 \%$ of cell-wall-bound phenolic acids. Maximal level reached 8,500 $\mu \mathrm{g} / \mathrm{g}$ whereas free ferulic acid never exceeded $200 \mu \mathrm{g} / \mathrm{g}$. At maturity, the amount of total ferulic acid ranged from 1,000 to $1,500 \mu \mathrm{g} / \mathrm{g}$, similar to the results of Assabgui and associates (1993) for European inbreeds but lower than the levels reported by Zilic and associates (2012) for colored maize genotypes. Because bibliographic data concerning phenolic acid accumulation during maize kernel development are scarce, it is actually not possible to compare the concentrations we determined in the earliest stages with previous reports.

According to our data, reduced concentrations in phenolic acids during ripening of soft and durum wheat grain were previously reported (McCallum and Walker 1990; McKeehen et al. 1999; Régnier and Macheix 1996) and ascribed to several rationales. First, the activities of phenyl-alanine ammonialyase and L-tyrosine ammonia-lyase, two crucial enzymes for the initial committed step in the biosynthesis of phenylpropanoids, were shown to be maximal during the early milk stage of grain (McCallum and Walker 1990; Régnier and Macheix 1996). Second, the rate of endosperm development surpasses the rate of synthesis of the outer coverings during kernel ripening, which leads to a dilution of the overall phenolic constituents within the kernel. Third, the decrease in oxidizable phenolic acids would result from the contact with peroxidase enzymes induced by the breakdown of cellular structure in the pericarp at the end of the milk stage and during further maturation (Régnier and Macheix 1996). Finally, the decrease in cell wall-bound phenolic acid contents can be correlated with the formation of alkali-resistant bounds occurring in cross-linked polymers in cell walls not extractable with the method we used in our study (Iiyama et al. 1994).

In conclusion, given the dynamics of phenolic acid accumulation we reported, the main phenolic acids $F$. graminearum potentially encounters when its mycotoxin production is initiated are chlorogenic, ferulic, caffeic, and $p$-coumaric acids. The present work is the first one demonstrating the great occurrence of chlorogenic acid before the blister stage.

\section{Fusarium infection leads to a significant increase in chlorogenic acid accumulation.}

Free chlorogenic acid was significantly more abundant in $F$. graminearum-infected kernels of both varieties. F. graminearum infection induced a significant increase in chlorogenic acid as early as 4 dai in kernels of the moderately resistant V2 variety and later, at 7 to 11 dai, in V1 kernels. In the V2 variety, chlorogenic acid induction was also accompanied by a slight but significant increase in ferulic and caffeic acid levels. This increase could result from the activities of the feruloyl esterases and xylanases secreted by $F$. graminearum during plant infection that release phenolic acids from the cell wall (Walter et al. 2010). However, we did not observe a significant decrease in cell-wall-linked ferulic acid in infected kernels (of both varieties). Unlike our data, such a decrease in ester-bound ferulic acid induced by maize silk inoculation and resulting from hemicellulose degradation by $F$. grami- nearum hydrolytic enzymes was previously reported by Cao and associates (2011).

Regarding DiFA, several reports aiming at elucidating hostparasite interactions have described their post-infection accumulation, supporting their role in plant resistance (Bily et al. 2003; Garcia-Lara et al. 2004; Ikegawa et al. 1996). Abundance of DiFA in the plant cell wall was shown to make polysaccharides less available to cell-wall-degrading enzymes of pathogens, therefore limiting fungal propagation (Ikegawa et al. 1996). In the present report, no significant difference between noninoculated and inoculated kernels was found. This observation could indicate that, in the maize tissues of the varieties we used, DiFA mainly function as preformed resistance barriers prior to infection.

In summary, our data strongly suggest that free chlorogenic acid could form a part of the plant response to F. graminearum infection. This conclusion is supported by the results of a transcriptomic analysis of the barley- $F$. graminearum interaction that indicated an overexpression of genes encoding enzymes involved in the phenylpropanoid pathway (Boddu et al. 2006). Furthermore, microarray analysis of $F$. graminearum-induced wheat genes showed that cinnamate-4-hydroxylase, the enzyme responsible for the conversion of $t$-cinnamic acid into $p$-coumaric acid, was upregulated in response to Fusarium infection (Golkari et al. 2007). All together, these experiments lead to the same idea-Fusarium infection activates the plant phenylpropanoid pathway, which leads to a significant increase in phenolic acid levels, including chlorogenic acid.

\section{Chlorogenic and ferulic acid are significantly more abundant in the moderately resistant variety versus the sensitive one.}

Although phenolic acid composition of kernels in their successive developmental stages was qualitatively similar for the two studied varieties, significant quantitative differences were observed. These differences were exclusively observed before the dough stages (Fig. 5B). At maturity and regardless the considered phenolic compound, no significant difference allowed discrimination of the two varieties. This observation, also supported by the results of Santiago and associates (2007), strongly highlights the importance of the early steps of infection to investigate the potential involvement of phenolic acids in Gibberella ear-rot resistance.

At the time DON production was initiated, kernels of the V2 variety were characterized by higher levels in free and cellwall-bound phenolic acids. At 4 dai, chlorogenic acid levels in V2 noninoculated and inoculated kernels were 10- and 25-fold higher than in V1 noninoculated and inoculated kernels, respectively. With regards to free and bound ferulic acid, $p$-coumaric acid, and DiFA, these differences were significant and never exceeded a fourfold factor. These results suggest that the former phenolic acids and, particularly, chlorogenic acid could be constitutive metabolites of the plant that are related to Gibberella ear-rot resistance and, therefore, could be considered as phytoanticipins. Similar results were obtained by McKeehen and collaborators (1999) who found that, at the first stage of wheat kernel development, Fusarium spp.-resistant cultivars synthesized twice the cell-wall-bound ferulic acid as susceptible cultivars. The involvement of cell-wall-bound ferulic acid, $p$-coumaric acid, and DiFA in Gibberella ear-rot resistance is also supported by their frequently reported key role in cell wall fortification, including resistance to cell-wall-degrading enzymes (Walter et al. 2010) and their direct in vitro effect in limiting Fusarium spp. growth (Ponts et al. 2011) and DON accumulation (Boutigny et al. 2009, 2010). Nonetheless, the present work is the first one highlighting the potential implication of chlorogenic acid in Gibberella ear-rot resistance. This 
hypothesis was corroborated by a complementary study: the phenolic acid compositions of maize kernels from 15 cultivars with different levels of resistance to Gibberella ear rot were characterized 15 days after anthesis. We found that the highest chlorogenic acid contents occurred in the more resistant varieties (Pons 2010). In addition, chlorogenic acid has been reported as a resistance factor in other various pathosystems, including peach-Monilia laxa (Villarino et al. 2011) or chrysanthemum-thrips (Leiss et al. 2009). Chlorogenic acid was also demonstrated to exhibit antifungal activities as the result of its ability to disrupt the structure of fungal cell membranes (Sung and Lee 2010) or because of its effect on fungal melanin production (Villarino et al. 2011).

To summarize, we have demonstrated that the main phenolic acids that $F$. graminearum is likely to encounter at the beginning of maize ear colonization and DON production are chlorogenic acid and, to a lesser extent, ferulic acid. Our results suggest that maize susceptibility to Fusarium infection and DON contamination could be linked to the in planta biosynthesis of chlorogenic and ferulic acids. Additional studies involving a larger range of maize varieties are now needed to confirm the potential use of chlorogenic acid as a resistance biomarker. The antifungal effect of ferulic acid together with its ability to downregulate the expression of the genes involved in DON biosynthesis by $F$. graminearum has been studied (Boutigny et al. 2009, 2010) but limited data are available with regards to chlorogenic acid. Finally, given the complexity of resistance mechanisms linked to a widely accepted polygenic mode, components other than phenolic acids certainly contribute to this mechanism. Past metabolomic profiling studies investigated Fusarium head blight resistance in mature wheat kernels (Browne and Brindle 2007; Hamzehzarghani et al. 2005) or mature barley kernels (Bollina et al. 2010; Kumaraswamy et al. 2011) and identified several potential constitutive and inducible resistance-related metabolites. However, our results presented here demonstrate that the greatest differences in phenolic composition occur at early stages of kernel development, when DON production is initiated. Therefore, the discovery of efficient resistance-associated plant factors should be undergone for those early stages of development.

\section{MATERIALS AND METHODS}

\section{Experimental set-up.}

Two field maize varieties, PR38H20 and DK291 (here referred to as V1 and V2, respectively) were sown in 2007 and
2008 in the southwest of France in a randomized complete block design with two replications. Each plot consisted of four rows of 30 plants. On the basis of previous evaluation by Arvalis-Institut du Végétal under natural contamination, V1 is susceptible to $F$. graminearum whereas V2 is moderately resistant. Daily temperatures and precipitations were measured using a meteorological station located near the experimental fields. Maize kernel stages were identified according to the number of days after silking (Nielsen 2001). Kernel moisture content was estimated according to the thermal time after silking (Borras et al. 2003; Sala et al. 2007) (Table 2).

The $F$. graminearum $\mathrm{P} 12$ strain (DON/15-ADON chemotype, provided by Monsanto), isolated from naturally infected maize in the southwest of France, was used. The strain was grown in a petri dish on potato dextrose agar medium (Difco Potato Dextrose Agar, $39 \mathrm{~g} /$ liter) supplemented with autoclaved white sorghum. Immediately after inoculation, autoclaved wooden toothpicks were placed on the surface of the petri dish so that they would be covered by the growing $F$. graminearum. Petri dishes were then stored at $4^{\circ} \mathrm{C}$ until inoculation.

Cobs were inoculated 5 days after silking (silking was assigned when silk emergence could be observed in $50 \%$ of maize ears) by introducing two toothpicks coated with $F$. graminearum mycelium into silk channels, taking care not to hurt the top of the corn, as described by Hart and associates (1982). For each variety, 10 inoculated maize ears were randomly handpicked at $0,4,7,11,23,50$, and 74 (maturity) dai. These values are mean of two years and two varieties (Table 2); 0 dai is the day of inoculation. Ten noninoculated maize ears were also sampled at $0,7,11$, and 74 dai in 2007 and at $0,4,7,11$, 20, 50, and 74 dai in 2008.

Young maize ears were directly dived into liquid nitrogen to remove kernels from the rachis. For 23-, 50-, and 74-dai sampling dates, ears were manually shelled and kernels were dived into liquid nitrogen. Kernels were then ground to a fine powder into liquid nitrogen with a Dangoumo blender, lyophilized (Flexi-Dry; Erlikon Leybold, Germany), and stored at $-80^{\circ} \mathrm{C}$ until further analysis.

DNA extraction and quantification of fungal DNA content.

Total DNA content was extracted from $100 \mathrm{mg}$ of ground kernels using the DNeasy plant mini kit according to the manufacturer's instructions (Qiagen, Courtaboeuf, France). Sample disruption was performed on a TissueLyser (Qiagen) in $400 \mu \mathrm{l}$ of AP1 Buffer (DNeasy plant mini kit; Qiagen) for $45 \mathrm{~s}$ at $30 \mathrm{~Hz}$ using one stainless-steel bead. Purified DNA

Table 2. Sowing date, flowering date, inoculation date, sampling dates, and kernel characteristics (kernel moisture content and stages) for each experiment

\begin{tabular}{|c|c|c|c|c|c|c|c|c|c|c|c|c|c|c|}
\hline \multirow[b]{4}{*}{ Date of } & \multicolumn{12}{|c|}{ Year, variety $^{x}$} & \multirow[b]{4}{*}{$\mathbf{K M}(\%)^{\mathbf{y}}$} & \multirow[b]{4}{*}{ Stage $^{z}$} \\
\hline & \multicolumn{6}{|c|}{2007} & \multicolumn{6}{|c|}{2008} & & \\
\hline & \multicolumn{3}{|c|}{ V1 } & \multicolumn{3}{|c|}{ V2 } & \multicolumn{3}{|c|}{ V1 } & \multicolumn{3}{|c|}{$\mathbf{V 2}$} & & \\
\hline & Date & dai & TT & Date & dai & TT & Date & dai & TT & Date & dai & TT & & \\
\hline Sowing & $20 \mathrm{Apr}$ & $\ldots$ & $\ldots$ & $20 \mathrm{Apr}$ & $\ldots$ & $\ldots$ & 21 May & ${ }^{2}$ & $\ldots$ & 21 May & $\ldots$ & .. & $\ldots$ & $\ldots$ \\
\hline Flowering & 29 June & $\ldots$ & $\ldots$ & 28 June & $\ldots$ & $\ldots$ & 30 July & $\ldots$ & $\ldots$ & 25 July & $\ldots$ & $\ldots$ & & $\ldots$ \\
\hline Inoculation & 09 July & 0 & 0 & 09 July & 0 & 0 & 04 Aug & 0 & 0 & 31 July & 0 & 0 & 90 & Silking \\
\hline \multirow[t]{6}{*}{ Sampling } & 13 July & 4 & 68 & 13 July & 4 & 68 & 08 Aug & 4 & 87 & 04 Aug & 4 & 84 & $85-90$ & Silking \\
\hline & 16 July & 7 & 144 & 16 July & 7 & 144 & 11 Aug & 7 & 145 & 08 Aug & 8 & 171 & $80-85$ & Blister \\
\hline & 20 July & 11 & 226 & 20 July & 11 & 226 & $14 \mathrm{Aug}$ & 10 & 201 & $11 \mathrm{Aug}$ & 11 & 229 & $70-80$ & Milk \\
\hline & 03 Aug & 25 & 508 & 03 Aug & 25 & 508 & 25 Aug & 21 & 410 & 20 Aug & 20 & 399 & $60-70$ & Dough \\
\hline & $28 \mathrm{Aug}$ & 50 & 1,001 & $28 \mathrm{Aug}$ & 50 & 1,001 & $23 \mathrm{Sept}$ & 50 & 964 & $23 \mathrm{Sept}$ & 54 & 1,048 & $40-50$ & Dent \\
\hline & $21 \mathrm{Sept}$ & 74 & 1,434 & $21 \mathrm{Sept}$ & 74 & 1,434 & 16 Oct & 73 & 1,318 & $16 \mathrm{Oct}$ & 77 & 1,402 & $<25$ & Maturity \\
\hline
\end{tabular}

${ }^{\mathrm{x}} \mathrm{V} 1$ = susceptible variety, $\mathrm{V} 2=$ moderately resistant variety, dai = days after inoculation, and TT = thermal time from inoculation $\left({ }^{\circ} \mathrm{C}\right.$ day $) ;$ Apr $=$ April, Aug = August, Sept $=$ September, and Oct $=$ October.

${ }^{\mathrm{y}}$ Estimated kernel moisture (KM) content according to the thermal time from silking, based on the methods of Borras and associate (2003) and Sala and associate (2007).

${ }^{\mathrm{z}}$ Maize kernel stage for each sampling was determined according to the number of days after silking based on the work of Nielsen (2001). 
was quantified by UV spectrometry (NanoDrop Technology, Cambridge, U.K.) and the concentration was systematically adjusted to $20 \mathrm{ng} / \mu \mathrm{l}$ with nuclease-free water. The contents of $F$. graminearum and Zea mays gDNA in each sample was measured by Q-PCR with SYBR green detection using a LightCycler real-time detector (Roche Applied Science, Meylan, France). We used the previously published F. graminearum-specific primer pair Fg16N (Nicholson et al. 1998) to amplify a $280 \mathrm{bp}$-long fragment of $F$. graminearum gDNA (amplification conditions: $1 \times$ for $15 \mathrm{~min}$ at $95^{\circ} \mathrm{C}$ and $45 \times$ for $15 \mathrm{~s}$ at $95^{\circ} \mathrm{C}, 25 \mathrm{~s}$ at $60^{\circ} \mathrm{C}$, and $30 \mathrm{~s}$ at $\left.72^{\circ} \mathrm{C}\right)$. We amplified a 95-bp-long fragment of the housekeeping gene MAc1 (accession number J01238) coding for actin in Z. mays gDNA (Shah et al. 1983) using the primers TCCTGACACTGAAGT ACCCGATT and CGTTGTAGGTGTGATGCCAGTT (amplification conditions: $1 \times$ for $15 \mathrm{~min}$ at $95^{\circ} \mathrm{C}$ and $45 \times$ for $15 \mathrm{~s}$ at $95^{\circ} \mathrm{C}, 25 \mathrm{~s}$ at $57^{\circ} \mathrm{C}$, and $30 \mathrm{~s}$ at $72^{\circ} \mathrm{C}$ ). Each Q-PCR reaction consisted of $5 \mathrm{mM} \mathrm{MgCl} 2,0.5 \mu \mathrm{M}$ primers, $20 \mathrm{ng}$ of purified DNA, and $2 \mu \mathrm{l}$ of $5 \times$ LightCycler FastStart DNA Master SYBR green I (Roche Applied Science) or 5× QuantiTect SYBR green (Qiagen) in a final volume of $10 \mu \mathrm{l}$. All reactions were performed in triplicate.

Quantification was performed using external calibration curves with standard solutions consisting of $F$. graminearum gDNA extracted from pure cultures and maize gDNA extracted from a noncontaminated maize sample. Each standard curve was generated by serial dilutions of 50 to $5 \times 10^{-3} \mathrm{ng} / \mu \mathrm{l}$. PCR efficiency always ranged from 95 to $100 \%$, and $r^{2}$ values between the DNA concentration and cycle threshold were superior to 0.98 . The specificity of amplification was always verified by melting-curve analysis (thermal profile settings: $0 \mathrm{~s}$ at $95^{\circ} \mathrm{C}, 15 \mathrm{~s}$ at $70^{\circ} \mathrm{C}[\mathrm{Fg} 16 \mathrm{~N}]$ or $67^{\circ} \mathrm{C}$ [MAc1], and increase to $95^{\circ} \mathrm{C}$ with $0.1^{\circ} \mathrm{C} / \mathrm{s}$ increments). Relative quantification of the presence of fungal gDNA in the tested sample was expressed as $\log _{10}$ (quantity of fungal $\left.\mathrm{gDNA}\right) / \log _{10}$ (quantity of maize gDNA).

\section{TCTB extraction and LC-MS/MS analysis.}

TCTB were extracted by agitating $1 \mathrm{~g}$ of kernel powder with $5 \mathrm{ml}$ of acetonitrile/water $(84: 16$, vol/vol) for $1 \mathrm{~h}$. After centrifugation, $4 \mathrm{ml}$ of the filtrate were purified using Trichothecene $\mathrm{P}$ columns (R-Biopharm) before evaporation to dryness at $70^{\circ} \mathrm{C}$ and dissolution in $100 \mu \mathrm{l}$ of methanol/water (50:50, vol/vol). TCTB concentration was determined using HPLCMS/MS analyses according to the method described by Picot and associates (2012). Limit of quantification of LC-MS/MS analysis was $0.05 \mu \mathrm{g} / \mathrm{g}$ dry weight.

\section{Phenolic acid extraction and analysis.}

Phenolic extraction was performed using $500 \mathrm{mg}$ of lyophilized powders of maize kernels. Maize powders were defatted twice by stirring in hexane at a 1:5 ratio (wt/vol) for 10 min at ambient temperature and then extracted for $30 \mathrm{~min}$ with $10 \mathrm{ml}$ of $80 \%$ methanol in water. Samples were then centrifuged for $5 \mathrm{~min}$ at $1,000 \mathrm{rpm}$. The supernatants contain the free phenolics, and the pellets contain the ester-boundcell-wall phenolics. Free phenolic acids were concentrated to $5 \mathrm{ml}$ under a nitrogen stream at $40^{\circ} \mathrm{C}$, and $5 \mathrm{ml}$ of water was added. The aqueous solutions were acidified using $1 \mathrm{~N} \mathrm{HCl}$ to a $\mathrm{pH}$ of 2.0 before liquid-liquid extraction with $10 \mathrm{ml}$ of ethyl acetate. The ethyl acetate extracts were reduced to dryness under a nitrogen stream at $40^{\circ} \mathrm{C}$ and redissolved in 100 $\mu \mathrm{l}$ of methanol/water $(50: 50, \mathrm{vol} / \mathrm{vol})$ before analysis. The pellets $(100 \mathrm{mg})$ containing ester-bound phenols were hydrolyzed with $4 \mathrm{ml}$ of $2 \mathrm{~N} \mathrm{NaOH}$ and shaken for $2 \mathrm{~h}$ in the dark in a nitrogen atmosphere. The hydrolysis was stopped with $12 \mathrm{~N} \mathrm{HCl}$ until the $\mathrm{pH}$ reached 2.0. After centrifugation (5 min at 1,000 rpm), supernatants were extracted twice with $5 \mathrm{ml}$ of ethyl acetate. The organic phases were evaporated to dryness under a nitrogen stream at $40^{\circ} \mathrm{C}$. The final precipitates were dissolved in $100 \mu \mathrm{l}$ of methanol/water (50:50, vol/vol) before analysis.

Phenolic acids were quantified by HPLC-DAD using an Agilent Technologies 1100 series liquid chromatograph equipped with an auto sampler system, an Agilent DAD, and the ChemStation chromatography manager software (Agilent Technologies, Massy, France). Separation of phenolics was achieved on a ZORBAX SB-C18 column (250 by $4.6 \mathrm{~mm}, 5 \mu \mathrm{m}$; Agilent) maintained at $30^{\circ} \mathrm{C}$. The mobile phase consisted of $2 \%$ formic acid in water ( $\mathrm{vol} / \mathrm{vol}$ ) (solvent $\mathrm{A}$ ) and acetonitrile (solvent B) according to the following gradient: 5 to $15 \% \mathrm{~B}$ for $30 \mathrm{~min}, 15$ to $50 \% \mathrm{~B}$ for $20 \mathrm{~min}, 50$ to $90 \%$ B for $8 \mathrm{~min}, 90 \%$ $\mathrm{B}$ for $5 \mathrm{~min}, 90$ to $5 \% \mathrm{~B}$ for $2 \mathrm{~min}$, and $5 \% \mathrm{~B}$ for $10 \mathrm{~min}$ postrun reconditioning. The sample injection volume was $5 \mu$ l. The flow rate was kept at $1 \mathrm{ml} / \mathrm{min}$ for a total run time of $75 \mathrm{~min}$. The UV-VIS spectra were recorded from 200 to $550 \mathrm{~nm}$. Quantification of phenolic acid monomers was performed by using external calibration with standard solutions prepared from commercial powders purchased from Sigma-Aldrich (France). The dimers of ferulic acid (8-5'-DiFA, 5-5'-DiFA, 8-O-4'-DiFA, and 8-5'-benzofuran-DiFA), CFP, and DFP were quantified using an external 8-5'-benzofuran-DiFA standard (chemically synthesized in our laboratory, purity $>$ $86 \%$ ) (Boutigny et al. 2010). Peak areas were converted to milligram/liter equivalent 8-5'-benzofuran-DiFA and final results were converted into microgram per gram of dry maize powder. Phenolic acid structures were resolved by LC-ESI/MS according to the method described by Boutigny and associates (2010).

\section{Statistical analyses.}

Statistical analyses were performed using XLSTAT 2008 software (Addinsoft, Rennes, France). Because a preliminary ANOVA indicated nonsignificant year-treatment interactions for all studied variables (TCTB, $F$. graminearum gDNA, and all phenolic compounds) and nonsignificant year-variety interactions for all variables except TCTB $(P=0.015)$, the data were pooled over the two years of experiments (Supplementary Table $\mathrm{S} 1$ ).

Data were log-transformed (variable +1 ) to ensure normal distributions of residues and homogeneity of variance.

One-way ANOVAs for TCTB, $F$. graminearum gDNA, and all phenolic compounds were carried out. Differences between harvest time in terms of fungal gDNA, TCTB, and phenolic compounds were determined separately for each variety and each treatment with multiple comparisons tests using the Duncan method.

Comparisons of means among varieties and inoculation treatments for each harvest time were made by two-tailed Student's $t$ test.

The level of significance was set at $P=0.05$ while the 0.10 level was taken to indicate a marginal effect.

\section{ACKNOWLEDGMENTS}

We gratefully acknowledge N. Ponts for her valuable comments.

\section{LITERATURE CITED}

Asran, M. R., and Buchenauer, H. 2003. Pathogenicity of Fusarium graminearum isolates on maize (Zea mays L.) cultivars and relation with deoxynivalenol and ergosterol contents. J. Plant Dis. Prot. 110:209-219.

Assabgui, R. A., Reid, L. M., Hamilton, R. I., Arnason, and J. T. 1993. Correlation of kernel (E)-ferulic acid content of maize with resistance to Fusarium graminearum. Phytopathology 83:949-953. 
Bai, G. H., Plattner, R., Desjardins, A., and Kolb, F. 2001. Resistance to Fusarium head blight and deoxynivalenol accumulation in wheat. Plant Breed. 120:1-6.

Beekrum, S., Govinden, R., Padayachee, T., and Odhav, B. 2003. Naturally occurring phenols: a detoxification strategy for fumonisin B1. Food Addit. Contam. 20:490-493.

Berthiller, F., Dall'asta, C., Corradini, R., Marchelli, R., Sulyok, M., Krska, R, Adam, G, and Schuhmacher, R. 2009. Occurrence of deoxynivalenol and its 3-D-glucoside in wheat and maize. Food Addit. Contam. 26:507-511.

Bily, A. C., Reid, L. M., and Taylor, J. H. 2003. Dehydrodimers of ferulic acid in maize grain pericarp and aleurone: resistance factors to Fusarium graminearum. Phytopathology 93:712-719.

Boddu, J., Cho S., Kruger, W., and Muehlbauer, G. J. 2006. Transcriptome analysis of the barley- Fusarium graminearum interaction. Mol. PlantMicrobe Interact. 19:407-417.

Bollina, V., Kumaraswamy, G. K., Kushalappa, A. C., Choo, T. M., Dion, Y., Rioux, S., Faubert, D., and Hamzehzarghani, H. 2010. Mass spectrometry-based metabolomics application to identify quantitative resistance-related metabolites in barley against Fusarium head blight. Mol. Plant Pathol. 11:769-782.

Borras, L., Westgate, M. E., and Otegui, M. E. 2003. Control of kernel weight and kernel water relations by post-flowering source-sink ratio in maize. Ann. Bot. 91:857-867.

Boutigny, A.-L., Richard-Forget, F., and Barreau, C. 2008. Natural mechanisms for cereal resistance to the accumulation of Fusarium trichothecenes. Eur. J. Plant Pathol. 121:411-423.

Boutigny, A.-L, Barreau C., Atanasova-Penichon, V., Verdal-Bonnin, M-N, Pinson-Gadais, L., and Richard-Forget, F. 2009. Ferulic acid, an efficient inhibitor of type B trichothecene biosynthesis and Tri gene expression in Fusarium liquid cultures. Mycol. Res. 113:746-753.

Boutigny, A.-L., Atanasova-Penichon, V., Benet, M., Barreau, C., and Richard-Forget, F. 2010. Natural phenolic acids from wheat bran inhibit Fusarium culmorum trichothecene biosynthesis in vitro by repressing Tri gene expression. Eur. J. Plant Pathol. 127:275-286.

Browne, R. A., and Brindle, K. M. 2007. 1H NMR-based metabolite profiling as a potential selection tool for breeding passive resistance against Fusarium head blight (FHB) in wheat. Mol. Plant Pathol. 8:401410

Bunzel, M. 2010. Chemistry and occurrence of hydroxycinnamate oligomers. Phytochem. Rev. 9:47-64.

Bunzel, M., Ralph, J., Bruning, P., and Steinhart, H. 2006. Structural identification of dehydrotriferulic and dehydrotetraferulic acids isolated from insoluble maize bran fiber. J. Agric. Food Chem. 54:6409 6418.

Cao, A., Reid L. M., and Butron, A. 2011. Role of hydroxycinnamic acids in the infection of maize silks by Fusarium graminearum Schwabe. Mol. Plant-Microbe Interact. 24:1020-1026.

Carter, J. P., Rezanoor, H. N., Holden, D., Desjardins, A. E., Plattner, R D., and Nicholson, P. 2002. Variation in pathogenicity associated with the genetic diversity of Fusarium graminearum. Eur. J. Plant Pathol. 108:573-583

Choi, S. W., Lee, S. K., Kim, E. O., Oh, J. H., Yoon, K. S., Parris, N., Hicks, K. B., and Moreau, R. A. 2007. Antioxidant and antimelanogenic activities of polyamine conjugates from corn bran and related hydroxycinnamic acids. J. Agric. Food Chem. 55:3920-3925.

Chulze, S. N. 2010. Strategies to reduce mycotoxin levels in maize during storage: a review. Food Addit. Contam. 27:651-657.

Edwards, S. G. 2004. Influence of agricultural practices on Fusarium infection of cereals and subsequent contamination of grain by trichothecene mycotoxins. Toxicol. Lett. 153:29-35.

Eggert, K., Hollmann, J., Hiller, B., Kruse, H.-P., Rawel, H. M., and Elke, P. 2010. Effects of Fusarium infection on the phenolics in emmer and naked barley. J. Agric. Food Chem. 58:3043-3049.

Garcia-Lara, S., Bergvinson, D. J., Burt, A. J., Ramputh, A. I., DiazPontones, D. M., and Arnason, J. T. 2004. The role of pericarp cell wall components in maize weevil resistance. Crop Sci. 44:1546-1552.

Golkari, S., Gilbert, J., Prashar, S., and Procunier, J. D. 2007. Microarray analysis of Fusarium graminearum-induced wheat genes: identification of organ-specific and differentially expressed genes. Plant Biotechnol. J. 5:38-49.

Hamzehzarghani, H., Kushalappa, A. C., Dion, Y., and Rioux, S. 2005. Metabolic profiling and factor analysis to discriminate quantitative resistance in wheat cultivars against Fusarium head blight. Physiol. Mol. Plant Pathol. 66:119-133.

Harris, L. J., Desjardins, A. E., Plattner, R. D., Nicholson, P., Butler, G., Young, J. C., Weston, G., Proctor, R. H., and Hohn, T. M. 1999. Possible role of trichothecene mycotoxins in virulence of Fusarium graminearum on maize. Plant Dis. 83:954-960.

Hart, L. P., Braselton, W. E, and Stebbins, T. C. 1982. Production of zeara- lenone and deoxynivalenol in commercial sweet corn. Plant Dis 66:1133-1135.

Hazel, C. M., and Patel, S. 2004. Influence of processing on trichothecene levels. Toxicol. Lett. 153:51-59.

Iiyama, K., Lam, T., and Stone, B. A. 1994. Covalent cross-links in the cell wall. Plant Physiol. 104:315-320.

Ikegawa, T., Mayama, S., Nakayashiki, H., and Kato, H. 1996. Accumulation of diferulic acid during the hypersensitive response of oat leaves to Puccinia coronata $\mathrm{f}$. sp. avenae and its role in the resistance of oat tissues to cell wall degrading enzymes. Physiol. Mol. Plant Pathol. 48:245-255.

Kumaraswamy, G., Bollina, V., Kushalappa, A., Choo, T., Dion, Y., Rioux, S., Mamer, O., and Faubert, D. 2011. Metabolomics technology to phenotype resistance in barley against Gibberella zeae. Eur. J. Plant Pathol. 130:29-43.

Leiss, K. A., Maltese, F., Choi, Y. H., Verpoorte, R., and Klinkhamer, P. G. L. 2009. Identification of chlorogenic acid as a resistance factor for thrips in chrysanthemum. Plant Physiol. 150:1567-1575.

Maier, F. J., Miedaner, T., Hadeler, B., Felk, A., Salomon, S., Lemmens, M., Kassner, H., and Schäfer, W. 2006. Involvement of trichothecenes in fusarioses of wheat, barley and maize evaluated by gene disruption of the trichodiene synthase (Tri5) gene in three field isolates of different chemotype and virulence. Mol. Plant Pathol. 7:449-461.

McCallum, J. A., and Walker, J. R. L. 1990. Phenolic biosynthesis during grain development in wheat (Triticum aestivum L.). Changes in phenylananine-ammonio-lyase activity and soluble phenolic content. J. Cereal Sci. 11:35-49.

McKeehen, J., Busch, R., and Fulcher, R. 1999. Evaluation of wheat (Triticum aestivum L.) phenolic acids during grain development and their contribution to Fusarium resistance. J. Agric. Food Chem. 47:14761482

Moreau, R. A., Nunez, A., and Singh, V. 2001. Diferuloylputrescine and $p$ coumaroyl-feruloylputrescine, abundant polyamine conjugates in lipid extracts of maize kernels. Lipids 36:839-844.

Nesci, A., Gsponer, N., and Etcheverry, M. 2007. Natural maize phenolic acids for control of aflatoxigenic fungi on maize. J. Food Sci. 72:180 185.

Nicholson, P., Simpson, D. R., Weston, G., Rezanoor, H. N., Lees, A. K., Parry, D. W., and Joyce, D. 1998. Detection and quantification of Fusarium culmorum and Fusarium graminearum in cereals using PCR assays. Physiol. Mol. Plant Pathol. 53:17-37.

Nicholson, R. L., and Hammerschidt, R. 1992. Phenolic compounds and their role in disease resistance. Annu. Rev. Phytopathol. 30:369-389.

Nielsen, R. L. B. 2001. Grain fill stages in corn. Department of Agronomy, Purdue University, West Lafayette, IN, U.S.A. Published online. www.kingcorn.org/news/timeless/GrainFill.html.

Palumbo J. D., O'Keeffe T. L., and Mahoney N. E. 2007. Inhibition of ochratoxin A production and growth of Aspergillus species by phenolic antioxidant compounds. Mycopathologia 164:241-248.

Picot, A., Barreau ,C., Pinson-Gadais, L., Piraux, F., Caron, D., Lannou, C., and Richard-Forget, F. 2011. The dent stage of maize kernels is the most conducive for fumonisin biosynthesis under field conditions. Appl. Environ. Microbiol. 77:8382-8390.

Picot, A., Hourcade-Marcolla, D., Barreau, C., Pinson-Gadais, L., Caron, D., Richard-Forget, F., and Lannou, C. 2012. Interactions between Fusarium verticillioides and Fusarium graminearum in maize ears and consequences for fungal development and mycotoxin accumulation. Plant Pathol. 61:140-151.

Pons, S. 2010. Importance du choix variétal dans la maîtrise des niveaux de contamination en trichothécènes $\mathrm{B}$ des récoltes de maïs. $\mathrm{Ph} . \mathrm{D}$. thesis, Bordeaux I University, France.

Ponts, N., Pinson-Gadais, L., Boutigny, A.-L., Barreau, C., and RichardForget, F. 2011. Cinnamic-derived acids significantly affect Fusarium graminearum growth and in vitro synthesis of type B trichothecenes. Phytopathology 101:929-934.

Régnier, T., and Macheix, J.-J. 1996. Changes in wall-bound phenolic acids, phenylalanine and tyrosine ammonia-lyases, and peroxidases in developing durum wheat grains (Triticum turgidum L. var. durum). J. Agric. Food Chem. 44:1727-1730.

Reid, L. M., and Sinha, R. C. 1998. Maize maturity and the development of Gibberella ear rot symptoms and deoxynivalenol after inoculation. Eur. J. Plant Pathol. 104:147-154.

Sala, R. G., Andrade, F. H., and Westgate, M. E. 2007. Maize kernel moisture at physiological maturity as affected by the source-sink relationship during grain filling. Crop Sci. 47:711-716.

Santiago, R., and Malvar, R. 2010. Role of dehydrodiferulates in maize resistance to pests and diseases. Int. J. Mol. Sci. 11:691-703.

Santiago, R., Reid, L. M., Arnason, J. T., Zhu, X., Martinez, N., and Malvar, R. A. 2007. Phenolics in maize genotypes differing in susceptibility to Gibberella stalk rot (Fusarium graminearum Schwabe). J. Agric. Food 
Chem. 55:5186-5193.

Shah, D. M., Hightower, R. C., and Meagher, R. B. 1983. Genes encoding actin in higher plants: intron positions are highly conserved but the coding sequences are not. J. Mol. Appl. Genet. 2:111-126.

Siranidou, E., Kang, Z., and Buchenauer, H. 2002. Studies on symptom development, phenolic compounds and morphological defence responses in wheat cultivars differing in resistance to Fusarium head blight. J. Phytopathol. 150:200-208.

Sung, W. S., and Lee, D. G. 2010. Antifungal action of chlorogenic acid against pathogenic fungi, mediated by membrane disruption. Pure Appl. Chem. 82:219-226.
Villarino, M., Sandin-Espana, P., Melgarejo, P., and De Cal, A. 2011. High chlorogenic and neochlorogenic acid levels in immature peaches reduce Monilinia laxa infection by interfering with fungal melanin biosynthesis. J. Agric. Food Chem. 59:3205-3213.

Walter, S., Nicholson, P., and Doohan, F. 2010. Action and reaction of host and pathogen during Fusarium head blight disease. New Phytol. 185:54-66.

Zilic, S., Serpen, A., Akillioglu, G., Gokmen, V., and Vancetovic, J. 2012. Phenolic compounds, carotenoids, anthocyanins, and antioxidant capacity of colored maize (Zea mays L.) kernels. J. Agric. Food Chem. 60:1224 1231. 